\title{
EL PRESTIGIO DEL DEVENIR CÍCLICO: LAS HIEROFANÍAS SELÉNICAS
}

\author{
Kattia Chinchilla Sánchez
}

\begin{abstract}
RESUMEN
Decir luna es decir alternancia y eterna esperanza de regeneración. Es por ello que las hierofanías selénicas se hallan involucradas con todos los procesos que encierran la alternativa en los ciclos -amén de sus fases-, esto es, todo lo cambiante, a saber, la vegetación, la fertilidad, la mujer, las aguas. Sin embargo, con base en la decrepitud del astro nocturno, el homo religiosus se sintió pronto involucrado en el destino lunar e hizo de esta mostración sacra su propia realidad luego del deceso físico: nacer-crecer-decrecer-morir-renacer. En el presente artículo, habremos de escudriñar la inexorable ley del devenir cíclico, principio regente de la regeneración cósmica.
\end{abstract}

\begin{abstract}
When we think about the moon, we can understand all the mystery of the cosmical regeneration. So the selenic hierophanies show us the ciclical cosmic way: vegetation, fertility, woman changes, waters. Despite the moon phases, the homo religiosus feel that his destiny is the same: born-growdecrease-die-reborn. This article studies the ciclical becoming law, taking the change of moon as a major postulate of universal renegeration.
\end{abstract}

Al ser la luna un astro alternativo y capaz de mostrar un ciclo completo, el tiempo fue medido, probablemente en todas partes del globo terráqueo, mediante una adaptación de las fases del astro nocturno a los intervalos periódicos de las actividades humanas. Pronto, las fases selénicas le revelaron al hombre el tiempo concreto, distinto del tiempo astronómico, que no se empleó sino hasta mucho más adelante. La vegetación, el ciclo de las estaciones, la fertilidad en toda la extensión del término, la mujer y el destino del humano, sugirieron al homo religiosus un nexo intrínseco con la ley del devenir cíclico, es decir, con todo el bagaje de las alternancias y sus implicaciones prácticas o metafísicas. La vegetación, por ejemplo, implica, tácita y prácticamente, las ideas de la muerte y el renacimiento, las nociones de la luz y de la oscuridad -valoradas como zonas cósmicas-, los lapsos de fecundidad y de carencia. Cabe aquí puntualizar que no existe ningún símbolo o emblema, monovalente o aislado, ya que el todo depende del todo: todo está vinculado colateralmente, a partir de la lógica mítico-simbólica y ese todo constituye en sí mismo un conjunto de estructura cósmica. 
Como toda hierofanía, la luna no fue adorada por sí misma, sino por lo que en ella había de sagrado, por lo que revelaba, es decir, la fuerza concentrada en ella, por la realidad y la vida inagotable que manifiesta: el devenir, que es la norma de la luna. Ella reparte, hila, mide y, otras veces, alimenta, fecunda, bendice o recibe las almas de los muertos, preside las iniciaciones y purifica el ámbito interno. El ritmo cíclico aparece siempre en los rituales lunares y promete la reintegración, amén de sus fases, que evidencian las alternativas por las cuales se atraviesa para lograr la regeneración absoluta: vida, decrepitud, muerte y renacimiento. La luna explicita la desintegración o fragmentación como un estadio previo a la reunión o reintegración, razón por la cual la araña y el huso le son afines. Por ejemplo, las Moiras que hilan el destino son divinidades lunares. Homero las llama las hilanderas y una de ellas lleva incluso el nombre de Klothó, es decir, la hilandera. Probablemente fueron en su origen divinidades del nacimiento, pero la evolución ulterior hizo de ellas la manifestación del destino. Sin embargo, su estructura lunar no se ha perdido nunca del todo, gracias al simple hecho de que "tejen”, parte y reparten, fragmentan y reúnen. La luna, entonces, al ser dueña de todas las cosas vivas y guía segura de los muertos, teje todos los destinos. No en vano aparece en los mitos como una inmensa araña, porque tejer no sólo significa predestinar (en el plano antropológico) y ensamblar realidades distintas (en el plano cosmológico) sino también crear, hacer salir de la propia sustancia, de la misma manera en que el arácnido produce de sí su propia tela.

\section{Rasgos selénicos determinantes}

El sol es siempre igual a sí mismo, no cambia, no transmuta sustancialmente, en definitiva, carece del devenir cíclico. En cambio, la luna, crece y decrece, desaparece y su transcurso está sujeto a la ley universal del devenir, del nacimiento y de la muerte. La luna, al igual que el ser humano, tiene un destino patético, porque su decrepitud -homologable con el envejecimiento y el deterioro subsecuente del hombre- desemboca en la muerte. Durante tres noches, la luna se ausenta del cielo estrellado. Pero a esta "muerte aparente" sigue siempre un renacimiento: la luna nueva. Esa desaparición de la luna en la oscuridad, en la "muerte", no es nunca definitiva, causa por la cual surgieron, en torno al astro de la noche, los cultos mistéricos de corte selénico. Esta vez, a diferencia de las solares, las iniciaciones lunares eran para un espectro social más amplio, que incluía hasta a las mujeres; de ningún modo exclusivo para las castas reinantes, como en el caso específico de los faraones egipcios. El destino postmortem del neófito se aseguraba por el regreso siempre seguro de la luna, tras los tres días de oscuridad, muestra de su muerte iniciática y de su transmutación radical e imperecedera de un estado a otro: vida-muerte-renacimiento, ad infinitum.

Es evidente, entonces, que la muerte no es definitiva y las fases de la luna son un buen ejemplo de la creencia en un renacimiento. En las ceremonias iniciáticas, se experimenta una muerte ritual, seguida de una vuelta a la vida y, así, el iniciado adquiere su verdadera personalidad de hombre nuevo. La iniciación mística consiste en un deceso ritual y transitorio, idéntico al de la luna. El tránsito del astro nocturno sugiere el eterno retorno hacia las formas iniciales, una periodicidad sin fin, que hace de la luna el astro por antonomasia de los ritmos vitales. Siendo así, no es de extrañar que controle todos los planos cósmicos sujetos a la ley del devenir cíclico: aguas, lluvia, vegetación, fertilidad. 
Comentábamos que el tiempo medido y controlado con el ajuste de las fases de la luna era un tiempo concreto, pero debemos agregar que es un tiempo vivo, pues se refiere siempre a una realidad biocósmica: a la lluvia o a las mareas, a la siembra o al ciclo menstrual. La influencia de la luna en la capacidad alternativa rige toda una serie de fenómenos en los planos cósmicos más diversos. El hombre anterior, quien conoció las virtudes de la luna, estableció relaciones de simpatía o de equivalencia entre esta serie de fenómenos. Por ejemplo, desde los tiempos más antiguos, desde el Neolítico al menos, emergió, en el momento en que se descubrió la agricultura, un simbolismo que vincula entre sí a la luna, las aguas, la lluvia, la fecundidad de la mujer y la de los animales, la vegetación, el destino del hombre después de la muerte y las ceremonias de iniciación, habiendo sido siempre el común denominador de estas la ley de devenir cíclico. El descubrimiento del ritmo lunar hizo posible esas síntesis mentales, las cuales unifican realidades aparentemente heterogéneas, que son expresadas de modo diverso en la red de asociaciones simbólicas universales.

Dícese que la luna es el primer muerto: durante tres noches, la luna desaparece del cielo, pero al cuarto día renace. Como ella, los muertos adquirirían un nuevo modo de existencia. La muerte no es una extinción, sino una modificación -casi siempre provisional- del plano vital. Dentro de la mentalidad religiosa, el muerto participa de otro tipo de existencia: los difuntos o sus almas van a la luna o vuelven bajo la tierra con el afán de regenerarse y de asimilar las fuerzas necesarias para una nueva vivencia. Esta es la razón por la cual muchas divinidades lunares son a la vez ctónicas y funerarias (Men, Perséfone, Hermes, Hécate).

El destino de la luna es vivir sin dejar de ser inmortal; conocer la muerte como reposo y como regeneración, pero nunca como un final. Ese es el destino que el hombre trata de alcanzar con sus ritos, símbolos y mitos.

\section{Alternatividad de los ritmos: fertilidad, mujer, aguas}

La fertilidad en toda su extensión (vegetal, animal y humana) depende de la luna, amén de su esencia cíclica. Sin embargo, el vínculo entre la fecundidad y la luna se complica, a veces, con la aparición de nuevas formas religiosas: la tierra madre, las divinidades agrarias, las deidades ctónicas. A pesar de esto, cualquiera que sea el número de síntesis religiosas que hayan contribuido a construir esas nuevas formas, hay un atributo lunar siempre presente: el de la fertilidad, el de la creación periódica, el de la vida inagotable. Los cuernos de bovino, por ejemplo, que caracterizan a las grandes divinidades de la fecundidad, son un emblema de la Magna Mater divina. Siempre aparecen en las distintas culturas, sea en la iconografía, sea en ídolos, sea en los bajorrelieves, sea en las monedas e indican la presencia de la gran diosa de la fertilidad, viendo, en la cornamenta, alguna de las fases lunares: creciente o menguante. Otro símbolo selénico en concordancia con la fecundidad es la serpiente, de la cual hablaremos en el apartado siguiente, con especial énfasis en sus rasgos ctónicos, región en la cual se desenvuelve el misterio de la vida, la muerte y el renacimiento, ora en el plano vegetal, ora en el plano óntico.

La luna es la fuente de toda fertilidad y rige, al mismo tiempo, el ciclo alternativo femenino, esto es, su ciclo menstrual, cuya duración se asemeja al período completo de las fases lunares, dentro de una mentalidad mítico-simbólica. Ahora bien, no perdamos de vista que la noción de fertilidad implica también su contrario, la esterilidad, y precisamente esa alternancia, 
tanto en la mujer como en la naturaleza misma, nos instala en el destino total de la luna (vidamuerte-renacimiento). Veamos: hay lapsos de esterilidad y de fertilidad, tanto en las especies como en la tierra misma; es decir, hay instantes aptos para el surgimiento de la vida, seguidos de períodos en los cuales no existe fecundación posible; después, el ciclo inicia nuevamente para evidenciar las alternativas descritas.

Retomando ideas, simbólicamente, la mujer se vincula con lo telúrico y con lo selénico a la vez, a partir de su capacidad de dar fruto y, por ende, de caracterizarse por la fertilidad que ostenta. Así, el conjunto luna-mujer-tierra es matriz de todas las formas vivientes. La mujer es involutiva, al igual que la luna, y, durante la actividad sexual, cada orgasmo implica su retorno hacia lo primordial, hacia el estado caótico del cual la vida procede. Cada mujer tiende a reflejar algún aspecto simbólico de las deidades telúrico-selénicas: pasajera, amante desconocida, la hermana en Cantar de los Cantares; el ánima, reflejo de la más alta trascendecia del hombre: el amor imposible (Beatriz, de Dante); el intelecto purificado (Sofía); la humilde y moral sierva (la Virgen María); la furiosa cazadora (Artemisa); la tentadora (la sirena); la sexualmente atractiva (Afrodita); la instintiva (Eva); la emocional (Helena de Troya); la gran madre (Gea); la bruja (Hécate); la piadosa (la Pietà); la apasionada vengativa (Medea); la heroína (Juana de Arco).

Ahora bien, tanto por estar sujetas a los ritmos sucesivos (lluvia, mareas) como por ser germinativas, las aguas están regidas por la luna. Todas las divinidades lunares conservan de manera más o menos clara atributos acuáticos. En algunos pueblos amerindios, la luna o la divinidad lunar es, a la vez, deidad de las aguas; por ejemplo, Tláloc, entre los aztecas (nahuas), era el dios de las aguas y, a la vez, poseía una especie de anteojos formados por dos serpientes entrelazadas, símbolos lunares.

La relación entre la luna y las mareas, observada por los griegos, celtas, egipcios, es conocida también por los campesinos costarricenses, quienes, desde cualquier punto del país, incluso logran entrever, en las manchas lunares, el estado de "bajamar" o "pleamar" en los puertos y, anteriormente, ese era el único medio para obtener tal información. Supónese que de hecho existe un nexo real entre el astro y las mareas del planeta: es el resultado de la atracción que ejercen el Sol y la Luna sobre las aguas. El producto de la atracción es una función del sitio relativo de esos astros con respecto a la Tierra y, como dichas posiciones se suceden en forma periódica, el fenómeno de las mareas resulta también cíclico.

Desde esta perspectiva del devenir, el diluvio corresponde a los tres días de oscuridad, al lapso de muerte de la luna. Es un cataclismo, pero que no es nunca definitivo, puesto que tiene lugar bajo el signo de la luna y de las aguas, es decir, bajo el signo de la germinación y la regeneración. El diluvio destruye porque las formas están agotadas, pero tras él viene siempre una nueva humanidad y una nueva historia. Casi todos los mitos del diluvio cuentan cómo ha sobrevivido un único individuo, del que desciende la nueva raza humana. No obstante, el diluvio, primero como mito escatológico y segundo como hierofanía acuática, será abordado en un artículo aparte.

\section{Hécate: la serpiente, la muerte y las fuerzas ctónicas}

Por ser lunar, por vivir bajo la tierra y por encarnar el espíritu de los muertos, la serpiente conoce todos los secretos, es la fuente de la sabiduría y entrevé el futuro. Como atributo de la 
gran diosa, la serpiente conserva su carácter lunar (de regeneración cíclica) junto con el carácter telúrico. Puntualicemos. La sierpe se arrastra por la tierra, vive en sus oquedades y transmuta su piel -abandona su antiguo estado y "renace" siempre joven. Asimismo, desde el punto de vista simbólico, sus anillos expresan la eternidad del devenir cíclico. En cierto momento, la luna es identificada con la tierra, como hemos señalado, valoradas ambas como matrices de todas las formas vivientes. Las grandes diosas participan tanto del carácter sagrado del suelo como de la luna. Y como estas diosas son además divinidades funerarias (los muertos van a las regiones subterráneas o a la luna para regenerarse y reaparecer bajo una nueva forma), la serpiente se convierte en el animal funerario y ctónico por excelencia. Es momento para ocuparnos de una diosa griega que aglutina tales nociones: Hécate.

En Grecia, Hécate, divinidad de los muertos, quien preside las apariciones de fantasmas y sortilegios, protectora de las hechiceras, posee poderes temibles durante su ámbito nocturno de acción. Se le representa iconográficamente como una mujer con tres cuerpos, a veces adosada a una columna. Su triple aspecto sugiere la trinidad de la evolución lunar (crecimiento, decrecimiento, desaparición) o el triple dominio cósmico (cielo, tierra e infierno); sería, así, una diosa axial.

Se le adoraba principalmente en las encrucijadas, valoradas como lugares mágicos, porque simbolizan las deliberaciones del destino o de las opciones, vinculadas con las fuerzas ctónicas, que "atan", como una especie de fuerza de gravedad simbólica. Por cada decisión por elegir en un cruce, se regula no sólo la dirección horizontal en la superfice de la tierra, sino también una dirección vertical hacia uno u otro nivel elegido. Nótese que las ataduras son tanto uránicas como ctónicas, de ahí el atributo de la diosa: un látigo.

Divinidad ctónica y selénica, está asimilada con los cultos de la fertilidad. Gracias a la coincidentia oppositorum, presenta facetas benévolas y malévolas; preside las germinaciones y los nacimientos; protege las navegaciones marítimas; dispensa la prosperidad, la elocuencia, las mieses y la pesca; guía las purificaciones por la vía órfica. Vemos rasgos ya descritos: conjunto luna-fertilidad-iniciación. Por otra parte, es la diosa de los espectros, monstruos terroríficos; es la maestra de la magia, de los encantamientos, de los filtros. Aquí el aspecto notorio de las prácticas mágicas nos lleva a la reflexión de que dicha actividad posee sustento selénico, pues es capaz, según sus creyentes, de transmutar los estados varios, es decir, está vinculada con la ley del devenir.

Con el apelativo griego de Empousa, Hécate es polimorfa y adquiere aspecto de perro, mujer con cabeza de perro (o de león o de caballo o de vaca), de anciana gigante con cabellos de serpiente. Una cabellera de ese aspecto involucra lo selénico y lo ctónico-vegetal a la vez: el pelo es capaz de regenerarse (lo viejo por lo nuevo) al igual que la serpiente, es decir todos los elementos involucrados se relacionan entre sí por el devenir cíclico, esencia de lo lunar.

\section{Xochiquetzal y la vegetación}

Los profundos nexos entre la luna, la lluvia y la vegetación se intuían ya antes del descubrimiento de la agricultura. De esa misma fuente de fertilidad universal deriva también el mundo de las plantas, sometido a esa misma periodicidad, regida por los ritmos lunares. El vínculo orgánico que une la luna y la vegetación es tan fuerte que muchísimos dioses de 
la fertilidad son, a la vez, divinidades lunares; por ejemplo, las diosas egipcias Hathor e Isis, Isthar, la Anaitis irania.

El conjunto luna-aguas-vegetación aparece sobre todo en el carácter sagrado de ciertas bebidas de origen divino, como el soma indio o el haoma iranio. Sin embargo, el licor divino que confiere la inmortalidad a quienes lo beben explicita la sacralidad concentrada en la luna, las aguas y la vegetación. Es la sustancia divina por excelencia, porque transmuta la vida en realidad absoluta, es decir, en inmortalidad.

Así, la embriaguez sagrada permite al hombre participar, aunque de manera fugaz e imperfecta, del modo de ser divino; es decir, hace posible la paradoja de ser realmente y vivir al mismo tiempo la ambigüedad de poseer una existencia plena y experimentar un devenir, ser fuerza y equilibrio en un solo instante. Las Ménades ingerían un hongo crudo, amanita muscaria, el cual produce alucinaciones, desenfrenos insensatos, visión profética, energía erótica y una notable fuerza muscular. Este hongo fue usado por los nórdicos frenéticos para adquirir una fuerza temeraria en las batallas. Se supone que el néctar y la ambrosía eran hongos intoxicantes, el amanita muscaria y especialmente el hongo estiercolero pequeño y delgado llamado panaeolus papilonaceus, que produce alucinaciones. Un hongo bastante parecido a este aparece en un jarrón ático entre los cascos del Centauro Neso. Según Graves (1989: 8), los dioses, para quienes estaba reservado el néctar y la ambrosía, eran reyes y reinas; de ahí el delito del rey Tántalo, el cual consistió en dar el alimento sagrado a los profanos, a los mortales (Odisea: XI, 582). En los Misterios, los iniciados juraban guardar silencio sobre lo que comían y bebían, tenían visiones inolvidables y se les prometía la inmortalidad. El néctar y el cyceon, bebida con sabor a menta que probó la diosa Deméter, también se identificaban con la palabra griega hongo. En Oaxaca, México, los indios masatecas ingieren un hongo llamado psilocybe y existen similitudes entre estos y los misterios báquicos: las Ménades acostumbraban arrancar las cabezas de sus víctimas, lo que podría referirse al desgarramiento de la cabeza del hongo sagrado.

Una diosa azteca vinculada con la vegetación y sus elementos es Xochiquetzal, la "flor de quetzal", "la flor preciosa". Algunos ven en ella el arquetipo de la mujer joven en plena sexualidad: es la amante paradigmática. Se identifica con la sensualidad, el deseo sexual y el placer en general. Aquí subrayamos el nexo de la deidad con la fertilidad propia de lo selénico. Contábase un mito que expresa la simbología que entraña el nombre de Xochiquetzal con las flores, las cuales son producto de sus genitales. Quetzalcóatl, cuando se estaba lavando su miembro viril, lanzó de sí su simiente y cayó encima de una piedra, de la cual nació el murciélago, que fue enviado luego para que mordiese a Xochiquetzal en sus partes íntimas. Mientras la diosa dormía, el murciélago le extrajo toda su vagina de un mordisco, la que entregó a los dioses, quienes la lavaron con agua y de la cual surgieron unas rosas de mal olor. Posteriormente, el mismo murciélago llevó una de esas rosas a Michtlantecuhtli, quien limpió la rosa con agua; de ahí que las rosas olorosas son llamadas "suchiles", porque su origen se dio a partir de la diosa Xochiquetzal. Nótese la función fecundadora del agua sobre el órgano sexual de la diosa (hierogamia simbólica: vagina-tierra/agua-cielo) y el clásico producto vegetal. El resultado de la hierogamia cósmica a menudo es una divinidad vegetal, como en el caso del ciclo eleúsico (Deméter-Zeus-Parséfone). Recordemos en este punto que tanto dioses como símbolos son hierofanías, en un sentido lato.

Volviendo al mito citado, Xochiquetzal expresa la fuerza de la sexualidad, la fuerza de la fertilidad -valores selénicos- dada la ley del devenir cíclico. Esposa de Tláloc y raptada por Tezcatlipoca, se dice que ella realizó el primer acto sexual y de sus cabellos se formó la 
primera mujer, pareja de Pilzintecuhtli, de quienes nació Cinteotl. Por lo tanto, la primera mujer sería un avatar de Xochiquetzal. Dada su actividad amorosa, es la protectora de las ahuianime, "alegradoras" o prostitutas libres, y de las maqui, prostitutas rituales, sacerdotisas compañeras de los jóvenes guerreros.

Preside el juego, el canto, la danza, las flores, la alegría, en definitiva, todo lo que es hermoso. Es la divinidad protectora de las labores femeninas, es la protectora de las tejedoras y las bordadoras, como la Atenea helénica, quien, por cierto, es lunar. Como conclusión, la diosa explicita por la fuerza de las flores, el poder de vegetación y, por ende, de la fertilidad, todos los elementos involucrados con la simbología selénica.

\section{Consideraciones finales}

Una hierofanía lunar no sólo reúne y fija todas las fuerzas selénicas que actúan en todos los planos cómicos, sino que instala al hombre, por la eficacia de un ritual, en el centro de esas fuerzas, aumentando su vitalidad, haciéndole más real y garantizándole una condición mejor después de su muerte. El hombre se vio a sí mismo en el devenir de la luna, no sólo porque también su vida, como la de todos los organismos, tenía un final, sino además, y sobre todo, porque el fenómeno de la luna nueva legitimaba su sed de regeneración, su esperanza de renacer.

No olvidemos que un objeto sagrado, cualquiera que sean su forma y su sustancia, es sagrado porque revela la realidad última o porque participa de ella. El objeto religioso encarna siempre algo: lo sagrado. Y lo encarna o por su facultad de ser (como el cielo, la luna, el sol, la tierra), por su forma (es decir, por ser símbolo, por ejemplo, el huso o el tejido) o por ser una hierofanía (un lugar determinado o una piedra se convierten en sagrados; un objeto determinado es santificado, consagrado por un ritual, por el contacto con otro objeto o persona sagrada).

Habiendo sido intuida la luna como algo que rige los ritmos, como una fuente de energía, de vida y de regeneración, ha tejido una verdadera red entre todos los planos cósmicos, creando simetrías y analogías entre fenómenos de esta infinita red, como por ejemplo el conjunto luna-lluvia-fertilidad-mujer-serpiente-muerte-regeneración periódica. Pero, a veces, se nos presentan algunos conjuntos parciales: serpiente-mujer-fecundidad, mujer-serpiente-magia. En el binomio serpiente-agua (o lluvia), no siempre está clara la subordinación de estas dos realidades de la luna. Infinidad de mitos hablan de serpientes o dragones que gobiernan las nubes, viven en estanques y alimentan de agua al mundo.

La integración del hombre en el cosmos se realiza cuando este logra armonizarse con los dos ritmos astrales, unificando la luna y el sol en su propia existencia. La unidad de esos dos centros de energía sacro-cósmica, el sol y la luna, tiene por finalidad reintegrarlos en una unidad primordial, indiferenciada y no fragmentada todavía por el acto de la creación cósmica.

Finalmente, las hierofanías selénicas son caracterizadas por:

a) fertilidad (aguas, vegetación, mujer)

b) regeneración periódica (simbolismo de la serpiente y de todos los animales lunares; el hombre nuevo, que sobrevive a una catástrofe acuática provocada por la luna; muerte y resurrección iniciáticas) 
c) tiempo y destino (la luna mide, teje los destinos, vincula entre sí los distintos planos cósmicos y las realidades heterogéneas)

d) devenir, cambio, señalado por la oposición luz-oscuridad (luna llena-luna nueva; mundo superior y mundo inferior, bien y mal) o por la polarización ser-no ser, virtual-actual (simbolismo de las latencias: noche oscura, oscuridad, muerte, simientes, larvas).

La luna liga entre sí, por su modo de ser, un sinnúmero de realidades y de destinos. Armonías, simetrías, asimilaciones, participaciones, coordinadas por los ritmos lunares, constituyen una trama sin fin, una red de hilos invisibles, los cuales ligan entre sí a los hombres, las lluvias, la vegetación, la fecundidad, la salud, los animales, la muerte, la regeneración, la vida, el destino post mortem.

\section{Bibliografía}

Biedermann, Hans. 1993. Diccionario de símbolos. Barcelona: Paidós.

Bolen, Jean Shinoda. 1984. Goddesses in Everywoman. New York: Harper Colophon Books.

Castiglioni, Arturo. 1972. Encantamiento y magia. México: F.C.E.

Chevalier, Jean. 1988. Diccionario de los símbolos. Barcelona: Herder.

Cirlot, Eduardo. 1985. Diccionario de símbolos. Barcelona: Labor.

Eliade, Mircea. 1974. Imágenes y símbolos. Madrid: Taurus.

1978. A History of Religious Ideas. Chicago: The University of Chicago Press.

1978. Tratado de historia de las religiones. Madrid: Cristiandad.

1981. Tratado de historia de las religiones. Madrid: Cristiandad.

1983. Mito y realidad. Barcelona: Labor/Punto Omega.

1984. La búsqueda. Buenos Aires: Aurora.

1985. Lo sagrado y lo profano. Barcelona: Labor/Punto Omega.

Frazer, James. 1982. La rama dorada. México: F.C.E.

Gómez Pérez Rafael. 1986. Los dioses griegos. Madrid: Rialp. 
González Torres, Yolotl. 1991. Diccionario de mitología y religión de Mesoamérica. México: Larousse.

Graves, Robert. 1989. Los mitos griegos. México: Alianza.

Grimal, Pierre. 1963. Mitologías de las estepas, de los bosques y de las islas. España: Larousse. 1984. Diccionario de mitología griega y romana. Barcelona: Paidós.

Hallam, Elizabeth. 1996. Gods and Goddesses. A threasury of Deities and Tales from World Mythology. New York: MacMillan.

Harding, M. Esther. 1971. Women's Mysteries. New York: Harper Colophon Books.

Homero. 1980. Odisea. México: Porrúa.

Johansson, Patrick. 1993. La palabra de los aztecas. México: Trillas. 1994. Voces distantes de los aztecas. México: Fernández Editores.

Lurker, Manfred. 1992. El mensaje de los símbolos. Barcelona: Herder.

Ruiz de Elvira, Antonio. 1988. Mitología clásica. Madrid: Gredos.

Sahagún, Bernardino de. 1956. Historia General de las cosas de Nueva España. México: Porrúa. 